\title{
Estimasi ketebalan lapisan sedimen permukaan berdasarkan pengukuran mikrotremor di Pemalang, Jawa Tengah
}

\author{
Urip Nurwijayanto Prabowo*, Sehah dan Akmal Ferdiyan \\ Program Studi Fisika, Fakultas MIPA, Universitas Jenderal Soedirman \\ Jalan Dr. Suparno No.61 Karangwangkal Purwokerto Jawa Tengah \\ *email: urip.np@unsoed.ac.id
}

\begin{abstract}
Abstrak - Ketebalan lapisan sedimen permukaan merupakan salah satu parameter yang menggambarkan kondisi geologi permukaan suatu daerah saat mengalami gempabumi. Ketebalan lapisan sedimen dapat diestimasi berdasarkan data pengukuran mikrotremor yang dianalisis menggunakan metode Horizontal to Vertical Spectral Ratio (HVSR). Pada penelitian ini dilakukan pengukuran mikrotremor sebanyak 5 titik di wilayah Pemalang, Jawa Tengah yang secara geologi tersusun atas aluvium berumur kuarter. Hasil pengolahan data mikrotremor menggunakan metode HVSR adalah frekuensi dominan daerah penelitian yang berkisar antara 1,56 - 11,56 Hz dan ketebalan lapisan sedimen permukaan berkisar antara 4,49-33,70 m. Ketebalan lapisan sedimen permukaan memiliki nilai yang semakin besar ke arah pantai (utara). Hasil analisis menunjukkan bahwa morfologi bedrock cenderung mengikuti pola dari ketebalan lapisan sedimen karena perbedaan elevasi permukaan yang relatif kecil pada titik pengukuran.
\end{abstract}

Kata kunci: mikrotremor, HVSR, ketebalan sedimen

Abstract - The thickness of the surface sediment layer is one of the parameters that describes the local site effect of an area when an earthquake occoured. The thickness of the sediment layer can be estimated based on microtremor measurements which were analyzed using the Horizontal to vertical Spectral Ratio (HVSR) method. In this study, 5 microtremor measurements were carried out in the Pemalang area, Central Java, which are geologically composed of quaternary alluvium. The result of microtremor data processing using the HVSR method were the dominant frequency of the study area which ranges from $1.56-11.56 \mathrm{~Hz}$ and the thickness of the surface sediment layer ranges from 4.49 - $33.70 \mathrm{~m}$. The surface sediment layer is getting thicker towards the coast (north). The analysis results show that the bedrock morphology tends to follow the pattern of the thickness of the sediment layer due to the relatively small difference in surface elevation at the measurement point.

Key words: microtremor, HVSR, sediment layer

\section{PENDAHULUAN}

Gempabumi merupakan salah satu bencana alam yang menyebabkan kerusakan bangunan dan korban jiwa. Tingkat kerusakan akibat gempabumi di suatu daerah dipengaruhi beberapa faktor antara lain jarak dari sumber gempabumi, magnitudo gempabumi dan kondisi geologi permukaan [1].

Kondisi geologi permukaan berkaitan dengan karakteristik lapisan sedimen di permukaan yang dapat memperbesar goncangan gelombang gempabumi yang disebut sebagai amplifikasi [2]. Fenomena amplifikasi menyebabkan suatu daerah dapat mengalami kerusakan yang besar meskipun lokasinya relatif jauh dari sumber gempabumi [3]. Fenomena amplifikasi dan korelasinya dengan tingkat kerusakan akibat gempabumi telah diteliti di beberapa lokasi antara lain di Meksiko [1], Kobe, Jepang [4], Yogyakarta [5].

Kondisi geologi permukaan yang mempengaruhi fenomena amplifikasi dan tingkat kerusakan adalah ketebalan dan tingkat kekompakan lapisan sedimen permukaan. Lapisan sedimen yang tebal menyebabkan suatu daerah menjadi rawan mengalami kerusakan bangunan akibat gempabumi [6]. Sedangkan tingkat kekompakan berkaitan dengan kekerasan batuan penyusun lapisan sedimen permukaan dimana daerah berbatuan lunak memperbesar efek amplifikasi dan menyebabkan kerusakan di daerah tersebut [1]. Lapisan sedimen permukaan dengan batuan yang lunak dapat berupa aluvium, tanah yang tebal, dan produk gunungapi yang belum terkonsolidasi [7]-[9].

Penentuan kondisi geologi permukaan suatu daerah dapat menggunakan data 
pengukuran mikrotremor yang diolah berdasarkan metode Horizontal to Vertical Spectral Ratio (HVSR). Mikrotremor merupakan getaran yang konstan pada permukaan bumi dan berasal dari aktivitas manusia dan fenomena alam. Amplitudo getaran mikrotremor berkisar antara $10^{-7}-10^{-5} \mathrm{~m}$ [10]. Sedangkan metode HVSR merupakan metode analisis data yang membandingkan spektrum mikrotremor vertikal dan horizontal [11]. Hasil analisis HVSR berupa kurva HVSR dimana tinggi puncak kurva disebut faktor amplifikasi dan frekuensi pada puncak kurva merupakan

Pada penelitian ini telah dilakukan pengukuran mikrotremor di wilayah Pemalang, Jawa Tengah karena memiliki kondisi geologi yang tersusun atas batuan aluvium berumur kuarter yang terdiri atas kerikil, pasir, lanau dan lempung [18] (Gambar 1). Selain itu Pemalang merupakan ibu kota kabupaten yang juga termasuk dalam jalur lalu lintas Pantura (Pantai Utara Jawa) sehingga menjadi pusat nilai frekuensi dominan lapisan sedimen permukaan di lokasi pengukuran [12], [13]. Frekuensi dominan merupakan frekuensi resonansi lapisan sedimen permukaan saat mencapai nilai amplifikasi maksimum. Nilai frekuensi dominan hasil pengukuran HVSR dapat digunakan untuk menyatakan ketebalan lapisan sedimen permukaan [14], [15] sedangkan nilai tinggi puncak kurva masih diragukan untuk dijadikan sebagai acuan tingkat amplifikasi karena amplifikasi dari puncak kurva HVSR berbeda dengan amplifikasi hasil seismogram [16], [17].

pemerintahan, industri, pendidikan dan jalur transportasi perdagangan yang terus berkembang. Pengukuran mikrotremor merupakan metode yang murah, mudah dan memiliki akurasi yang baik dalam menggambarkan kondisi geologi permukaan [19].

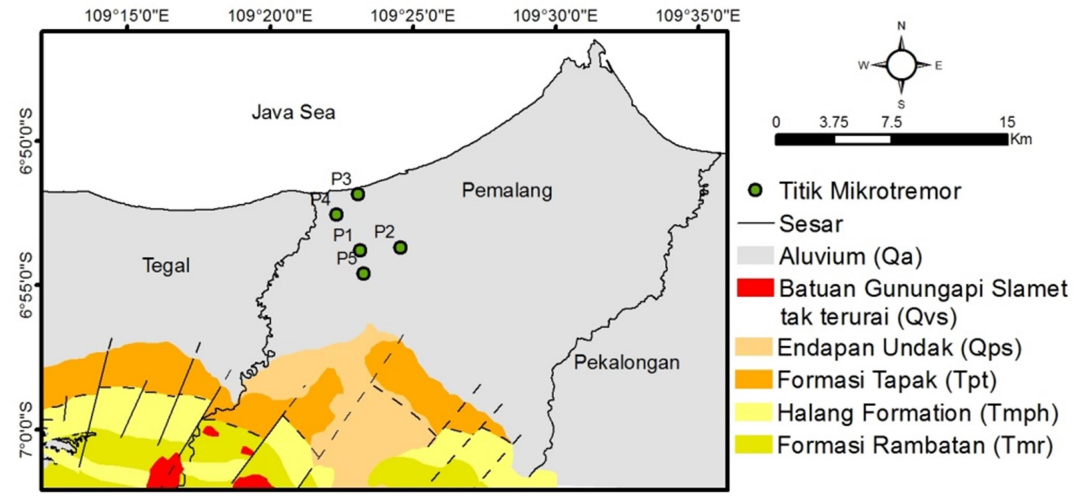

Gambar 1. Peta geologi daerah penelitian [18]

\begin{abstract}
Analisis data hasil pengukuran mikrotremor di wilayah Pemalang menggunakan metode HVSR bertujuan untuk menentukan ketebalan lapisan sedimen permukaan yang menggambarkan kondisi geologi permukaan. Selain itu ketebalan lapisan sedimen juga dapat menjadi acuan kedalaman lapisan keras (bedrock) yang digunakan untuk keperluan geoteknik atau konstruksi [20]
\end{abstract}

\section{METODE PENELITIAN}

Data mikrotremor diperoleh dari hasil pengukuran pada bulan Juli 2018 sebanyak 5 titik lokasi di wilayah Pemalang dengan koordinat 109,372 - 109,409 BT dan 6,864 6,910 LS. Pengukuran mikrotremor menggunakan seismometer 3 komponen tipe
MAE dengan sampling rate $4 \mathrm{mS}$ dan durasi pengukuran 20 menit pada tiap titik lokasi. Data kecepatan gelombang sekunder pada kedalaman 0-30 m $\left(V_{s 30}\right)$ didapatkan dari United States Geological Survey (USGS) yang merupakan nilai kecepatan rata-rata dari sedimen permukaan. Data ini akan digunakan untuk menentukan ketebalan lapisan sedimen permukaan karena belum ada data pengukuran kecepatan gelombang sekunder di wilayah Pemalang.

Gambar 2 memperlihatkan tahapan analisis data pada penelitian ini.

\section{Metode HVSR}


Pengolahan data mikrotremor dengan metode HVSR pada menggunakan software Geopsy. Tahapan awal pada metode HVSR adalah memilih sinyal rekaman mikrotremor 3 komponen yang stasioner dan tidak terpengaruh oleh noise atau sinyal dari lalu lintas dan aktivitas manusia di sekitar lokasi pengukuran. Sinyal stasioner yang dipilih selanjutnya dipotong (proses windowing) dengan lebar tiap window $\left(I_{w}\right) 20$ detik. Tiap data sinyal yang dipilih selanjutnya ditransformasikan dari domain waktu menjadi data dengan domain frekuensi melalui proses FFT (Fast Fourier Transform) dengan nilai tapering 5\%.

Data spektrum dalam domain frekuensi mengalami penghalusan (smoothing) dengan menggunakan metode Konno Omachi dengan konstanta $b=40$ [16]. Kemudian dilakukan perbandingan data yang telah dihaluskan pada 3 komponen data mikrotremor berdasarkan persamaan 1 [11]

$$
H V S R=\frac{\sqrt{H_{E W}^{2}+H_{N S}^{2}}}{V}
$$

dengan HVSR merupakan kurva hasil analisis, $V$ adalah spektrum komponen vertikal, $H_{E W}$ adalah spektrum komponen horizontal pada arah timur-barat, dan $H_{N S}$ adalah spektrum komponen horizontal pada arah utara-selatan.

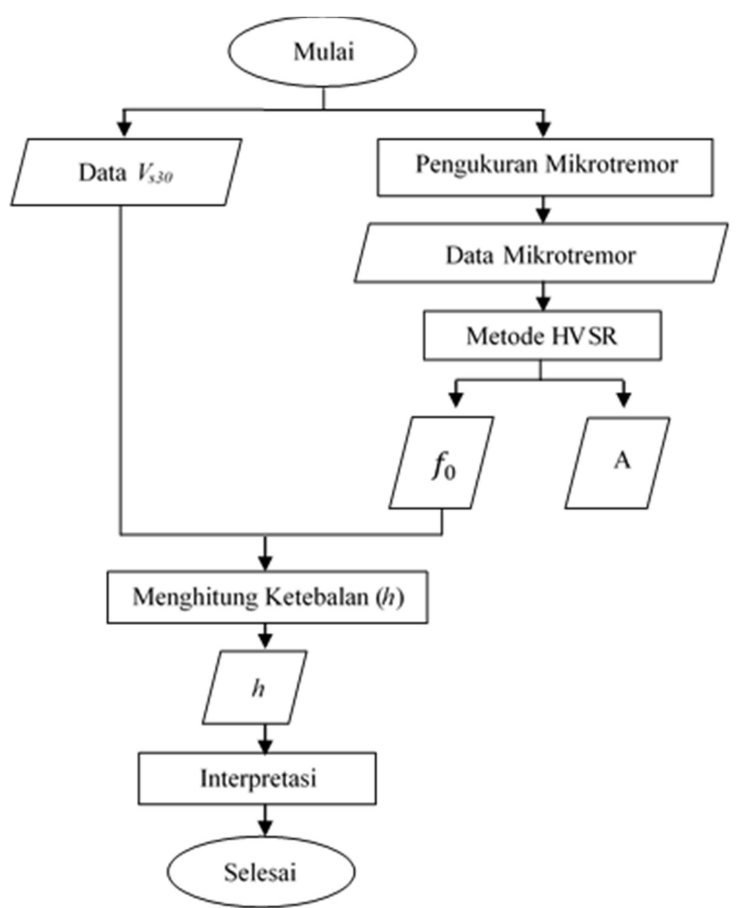

Gambar 2. Alur pengolahan data peneitian
Hasil kurva HVSR dibandingkan dengan kriteria pada Tabel 1 untuk menentukan puncak kurva HVSR yang reliabel sehingga nilai frekuensi dominan pada puncak kurva tersebut dapat digunakan pada analisis selanjutnya [16].

Tabel 1. Kriteria puncak kurva HVSR reliabel [16]

\begin{tabular}{|l|}
\hline Kriteria Puncak Kurva HVSR Reliabel \\
1) $f_{0}>\frac{10}{I_{w}}$ \\
2) $n_{c}\left(f_{0}\right)>200 ; n_{c}\left(f_{0}\right)=I_{w} . n_{w} \cdot f_{0}$ \\
3) $\sigma_{A}(f)<2$ untuk $0,5 f_{0}<f<2 f_{0}$ jika $f_{0}>0.5$ \\
Atau \\
$\sigma_{A}(f)<2$ untuk $0,5 f_{0}<f<2 f_{0}$ jika $f_{0}>0.5$ \\
Dengan \\
$f=$ frekuensi $\quad f_{0}=$ frekuensi dominan \\
$I_{w}=$ lebar window $\quad n_{w}=$ Jumlah window \\
$\sigma_{A}=$ standar deviasi dari tinggi kurva HVSR \\
\hline
\end{tabular}

\section{Perhitungan Ketebalan Lapisan Sedimen Permukaan}

Ketebalan lapisan sedimen permukaan memiliki kaitan dengan frekuensi dominan berdasarkan kaidah pipa organa tertutup dimana pada ketebalan lapisan sedimen $(h)$ bernilai $1 / 4$ panjang gelombang maka amplifikasi bernilai maksimum pada frekuensi resonansinya [14]. Berdasarkan prinsip tersebut maka ketebalan lapisan sedimen permukaan dapat ditentukan berdasarkan persamaan (2).

$$
h=\frac{V_{S}}{4 f_{0}}
$$

dengan $f_{0}$ adalah frekuensi dominan, $V_{S}$ adalah kecepatan gelombang sekunder dan $h$ adalah ketebalan lapisan sedimen permukaan.

\section{HASIL DAN PEMBAHASAN}

Hasil analisis metode HVSR adalah kurva HVSR pada 5 titik pengukuran. Hasil ini kemudian dibandingkan dengan kriteria pada Tabel 1 sehingga dapat diketahui hasil puncak kurva yang reliabel dan dapat digunakan untuk tahapan analisis selanjutnya yaitu menentukan ketebalan lapisan sedimen permukaan. 
Tabel 2 menunjukkan perbandingan kurva HVSR dengan kriteria puncak kurva HVSR reliabel dimana seluruh hasil kurva HVSR pada 5 titik pengukuran merupakan puncak kurva yang reliabel. Seluruh puncak kurva memenuhi kriteria reliabel yang pertama karena didapatkan nilai frekuensi yang berkisar antara 1,56-11,56 $\mathrm{Hz}$ yang lebih besar dari nilai $10 / I_{w}=0,5$. Pada kriteria kedua, seluruh hasil kurva juga memenuhi kriteria dengan nilai $n_{c}\left(f_{0}\right)>200$. Pada kriteria ketiga digunakan syarat yang pertama karena seluruh hasil kurva memiliki nilai frekuensi dominan lebih besar $0,5 \mathrm{~Hz}$. Terlihat dari Tabel 2 bahwa nilai standar deviasi antara $0,5 f_{0}<f<2 f_{0}$ tidak ada yang melebihi nilai 2 sebagai syarat standar sehingga kriteria puncak kurva reliabel ketiga juga terpenuhi. Pada kelima titik pengukuran, standar deviasi kurva antara $0,5 f_{0}<f<2 f_{0}$ memiliki rentang antara 1,06-1,61 Hz.

Pada Gambar 3 hasil HVSR menunjukkan nilai frekuensi dominan yang berkisar antara $1,56-11,56 \mathrm{~Hz}$ dengan nilai frekuensi yang semakin rendah ke arah pantai. Daerah pesisir pantai memiliki yang tersusun oleh material aluvium cenderung memiliki periode dominan yang tinggi (frekuensi yang rendah) [3]. Nilai frekuensi yang semakin rendah juga menunjukkan bahwa ketebalan sedimen permukaan yang semakin besar[14], [15].

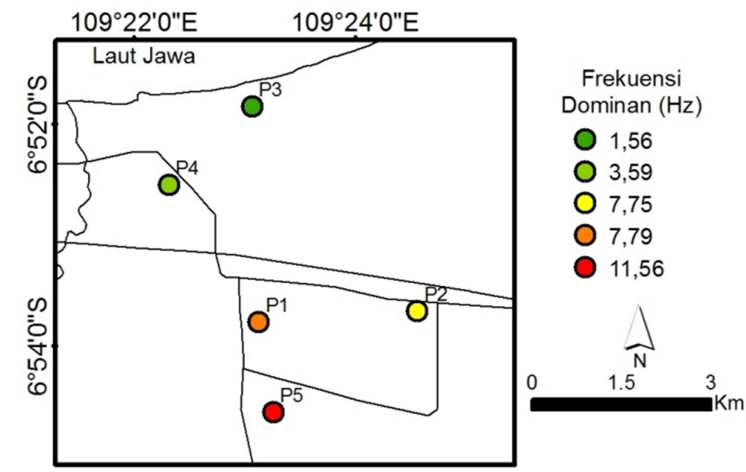

Gambar 3. Frekuensi dominan lokasi pengukuran mikrotremor

Tabel 2. Perbandingan kurva HVSR dengan kriteria kurva HVSR reliabel

\begin{tabular}{|c|c|c|c|c|c|c|c|c|c|}
\hline \multirow[b]{2}{*}{$\begin{array}{c}\text { Titik } \\
\text { Mikrotremor }\end{array}$} & \multirow[b]{2}{*}{ Bujur $\left({ }^{0}\right)$} & \multirow[b]{2}{*}{ Lintang $\left({ }^{0}\right)$} & \multirow[b]{2}{*}{$\begin{array}{c}f_{0} \\
(\mathrm{~Hz})\end{array}$} & \multirow[b]{2}{*}{ A } & \multicolumn{4}{|c|}{ Kriteria puncak kurva reliabel } & \multirow[b]{2}{*}{ Keterangan } \\
\hline & & & & & $f_{0} \rightarrow f^{-}$ & $f_{0}>\frac{10}{I_{w}}$ & $n_{c}\left(f_{0}\right)=I_{w} \cdot n_{w} \cdot f_{0}$ & $\begin{array}{c}\sigma_{A}(f) \\
0,5 f_{0}<f<2 f_{0}\end{array}$ & \\
\hline P1 & 109,386 & $-6,897$ & 7,94 & 6,23 & 25 & $f_{0}>0,5$ & 3970 & $1,11-1,25$ & $\begin{array}{l}\text { Memenuhi kriteria } \\
\text { reliabel }\end{array}$ \\
\hline $\mathrm{P} 2$ & 109,409 & $-6,895$ & 7,75 & 9,79 & 37 & $f_{0}>0,5$ & 5735 & $1,12-1.23$ & $\begin{array}{c}\text { Memenuhi kriteria } \\
\text { reliabel }\end{array}$ \\
\hline P3 & 109,385 & $-6,864$ & 1,56 & 7,78 & 18 & $f_{0}>0,5$ & 561,6 & $1,22-1,61$ & $\begin{array}{l}\text { Memenuhi kriteria } \\
\text { reliabel }\end{array}$ \\
\hline P4 & 109,372 & $-6,876$ & 3,59 & 6,47 & 18 & $f_{0}>0,5$ & 1292,4 & $1,12-1,44$ & $\begin{array}{c}\text { Memenuhi kriteria } \\
\text { reliabel }\end{array}$ \\
\hline P5 & 109,388 & $-6,910$ & 11,56 & 19,59 & 12 & $f_{0}>0,5$ & 2774,40 & $1,06-1,29$ & $\begin{array}{c}\text { Memenuhi kriteria } \\
\text { reliabel }\end{array}$ \\
\hline
\end{tabular}

Tabel 3 Perhitungan ketebalan lapisan sedimen permukaan

\begin{tabular}{cllcll}
\hline $\begin{array}{c}\text { Titik } \\
\text { Mikrotremor }\end{array}$ & Bujur $\left(^{0}\right)$ & Lintang $\left({ }^{0}\right)$ & $\begin{array}{c}f_{0} \\
(\mathrm{~Hz})\end{array}$ & $V_{S 30}(\mathrm{~m} / \mathrm{s})$ & $h(\mathrm{~m})$ \\
\hline P1 & 109,386 & $-6,897$ & 7,94 & 218,17 & 6,87 \\
P2 & 109,409 & $-6,895$ & 7,75 & 226,75 & 7,31 \\
P3 & 109,385 & $-6,864$ & 1,56 & 210,29 & 33,70 \\
P4 & 109,372 & $-6,876$ & 3,59 & 200,87 & 13,99 \\
P5 & 109,388 & $-6,910$ & 11,56 & 207,60 & 4,49 \\
\hline
\end{tabular}

Tabel 3 menunjukkan ketebalan lapisan sedimen yang dihitung berdasarkan nilai frekuensi dominan dan $V_{s 30}$ dari USGS menggunakan persamaan (2). Nilai frekuensi dominan merupakan hasil dari metode HVSR yang memenuhi kriteria puncak kurva yang reliabel. Nilai frekuensi dominan dan ketebalan lapisan sedimen yang didapatkan dari metode HVSR memberikan informasi penting dalam kajian kerentanan seismik [13], [21]. 
Gambar 4 menunjukkan sebaran nilai ketebalan lapisan sedimen permukaan di daerah penelitian dimana ketebalan lapisan sedimen permukaan semakin besar ke arah pantai (utara) yaitu pada titik P3 dengan ketebalan 33,70 m. Hal ini mengindikasikan kondisi geologi permukaan di titik P3 memiliki kemungkinan kerentanan kerusakan akibat gempabumi dibandingkan titik lokasi pengukuran yang lainnya. Lapisan sedimen yang tebal akan mengalami goncangan yang terasa lebih lambat dan dalam durasi yang lebih lama saat mengalami gempabumi sehingga nilai percepatan getaran tanahnya rendah [22]. Namun hal ini menyebabkan simpangan getarannya besar dan fenomena amplifikasi juga memperbesar getaran gempabumi sehingga dapat menyebabkan kerusakan tanah permukaan maupun bangunan di atasnya.

Berdasarkan hasil analisis data, daerah penelitian bagian selatan memiliki nilai ketebalan sedimen yang paling besar. Namun batas ketebalan lapisan sedimen yang dapat menyebabkan kerusakan saat mengalami gempabumi belum dapat ditentukan karena kerusakan akibat gempabumi juga dipengaruhi oleh parameter kegempaan berupa magnitudo gempabumi dan jarak sumber gempabumi ke daerah penelitian,

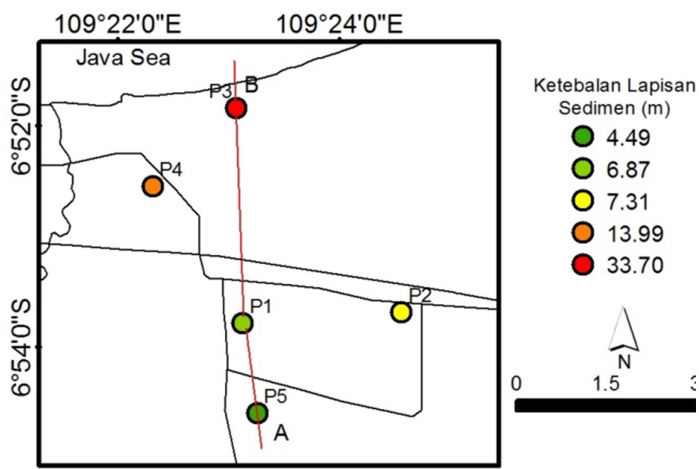

Gambar 4. Nilai ketebalan lapisan sedimen permukaan

Kedalaman dan profil dari bedrock dapat dilihat pada Gambar 5 yang merupakan gambar sayatan profil A-B (utara-selatan) dari Gambar 4.

Berdasarkan Gambar 5 daerah penelitian memiliki elevasi yang relatif sama karena berada pada dataran rendah sehingga ketinggian dan morfologi dari bedrock cenderung mengikuti pola dari sebaran ketebalan lapisan sedimen. Ketinggian bedrock terlihat semakin rendah ke arah utara mendekati pantai.
Pada metode HVSR, nilai amplifikasi menggambarkan kontras impedansi antara lapisan sedimen permukaan dengan lapisan batuan yang lebih keras di bawahnya (bedrock) [12]. Jenis batuan bedrock secara spesifik belum dapat ditentukan dari hasil metode HVSR sehingga pengukuran dengan metode lainnya perlu dilakukan untuk mendapatkan hasil yang lebih detail.

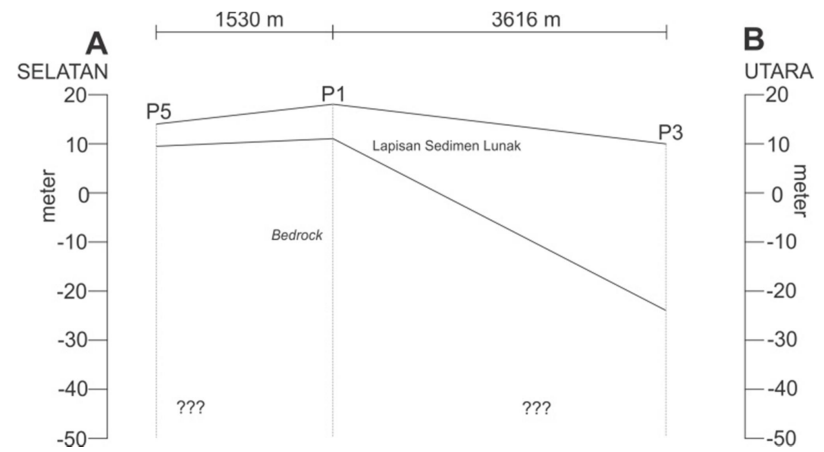

Gambar 5. Sayatan profil C-D (utara-selatan) dari Gambar 4

\section{KESIMPULAN}

Berdasarkan hasil pengukuran mikrotremor didapatkan nilai frekuensi dominan daerah penelitian berbanding terbalik dengan nilai ketebalan lapisan sedimen. Hasil perhitungan menunjukkan ketebalan lapisan sedimen permukaan berkisar antara 4,49 - 33,70 m dengan nilai yang semakin besar ke arah pantai (utara). Hasil analisis menunjukkan bahwa morfologi bedrock cenderung mengikuti pola dari ketebalan lapisan sedimen disebabkan perbedaan elevasi permukaan yang relatif kecil pada titik pengukuran.

\section{DAFTAR PUSTAKA}

[1] E. D. Gurler, Y. Nakamura, J. Saita, T. Sato, "Local site effect of mexico city based on microtremor measurement," in Proceeding of 6th International Conference of Seismic Zonation, 2000.

[2] U. N. Prabowo, Marjiyono, Sismanto, "Amplifikasi dan atenuasi gelombang seismik di lapisan sedimen permukaan," Sciencetech 2(1) (2016) 112-116,. 
[3] A. Tohari, "Seismic microzonation of soil amplification and liquefaction for Padang City," E3S Web Conf. 156, no. September 2009, , 2020, hal. 1-10.

[4] Y. Nakamura, T. Sato, and M. Nishinaga, "Local Site Effect Of Kobe Based On Microtremor," in Proceeding of the Sixth International Conference on Seismic Zonation EERI, Palm Springs California, 2000, hal. 3-8.

[5] Daryono, Sutikno, J. Sartohadi, Dulbahri, and K. S. Brotopuspito, "Efek Tapak Lokal ( Local Site effect ) di Graben Bantul Berdasarkan Pengukuran Mikrotremor," in International Conference Earth Science and Technology, 2009, hal. 4-9.

[6] S. B. J. Santosa, "Karakterisasi kurva Horizontal-To-Vertical Spectral Ratio: Kajian Literatur Dan Permodelan," $J$. Neutrino 4(1) (2011) 1-15.

[7] Marjiyono and Afnimar, "Mikrozonasi bahaya gempa bumi di wilayah kota bandung berdasarkan data mikrotremor," Geo-Hazards 21(1) (2011) 41-49

[8] R. W. P. Isburhan, G. Nuraeni, R. Verdhora Ry, T. Yudistira, A. Cipta, and P. Cummins, "Horizontal-to-Vertical Spectral Ratio (HVSR) Method for Earthquake Risk Determination of Jakarta City with Microtremor Data," IOP Conf. Ser. Earth Environ. Sci., 18(1) (2019).

[9] D. Stanko, S. Markušić, M. Gazdek, V. Sanković, and I. Slukan, "Assessment of the Seismic Site Amplification in the City of Ivanec ( NW Part of Croatia ) Using the Microtremor HVSR Method and Equivalent-linear Site Response Analysis," Geoscience 9(213) (2019) 1-25.

[10] H. Okada, "The Microtremor Survey Method," in Geophysical Monograph Series Number 12, Amerika: Society of Exploration Geophysicists, 2003.

[11] Y. Nakamura, "A Method for Dynamic Characteristics Estimation of Subsurface using Microtremor on the Ground Surface," QR RTR 30(1) (1989) 25-33.
[12] Y. Nakamura, "on the H / V Spectrum," Proc. 14th world Conf. Earthq. Eng., 2008.

[13]S. Y. Kang, K.-H. Kim, J.-M. Chiu, and L. Liu, "Microtremor HVSR analysis of heterogeneous shallow sedimentary structures at Pohang, South Korea," J. Geophys. Eng. (2020) 1-9.

[14] M. I. Seht and J. Wohlenberg, "Microtremor Measurements Used to Map Thickness of Soft Sediments," Bull. Seismol. Soc. Am. 89(1) (1999) 250-259.

[15] Marjiyono, Ratdomopurbo, Suharna, M. H. H. Zajuli, and R. Setianegara, "Geologi bawah permukaan dataran klaten berdasarkan interpretasi data mikrotremor," Geol. dan Sumberd. Miner. 5(1) (2014) 3 10.

[16] SESAME European Research Project, Guidelines For The Implementation Of The H / V Spectral Ratio Technique On Ambient Vibrations Measurements, Processing And Interpretation, 2004, pp. 162.

[17] B. Hassani, H. Zafarani, J. Farjoodi, and A. Ansari, "Estimation of site amplification, attenuation and source spectra of S-waves in the East-Central Iran," Soil Dyn. Earthq. Eng 31(10) (2011) 1397-1413.

[18] M. Djuri, H. Samodra, T. Amin, and S. Gafoer, "Geological Map of Purwokerto and Tegal Quadrangles, Java," Bandung, 1996.

[19] A. Mohamed, S. M. Ali, and A. Mostafa, "Estimation of seismic site effect at the new Tiba City proposed extension, Luxor, Egypt," NRIAG J. Astron. Geophys. 9(1) (2020) 499-511.

[20] A. Prabawa Arwananda, B. Aryaseta, H. Dezulfakar, Y. Fatahillah, and J. Pandu Gya Nur Rochman, "Horizontal-vertical Spectral Ratio Method in Microtremor to Estimate Engineering Bedrock Thickness at Sedati Mud Volcano," IOP Conf. Ser. Earth Environ. Sci. 62(1) 2017. 
[21] N. Haerudin, Rustadi, F. Alami, and I B S Yog, "The effect site analysis based on microtremor data using the Horizontal to Vertical Spectral Ratio ( HVSR ) method in the Bandar Lampung City," J. Phys. Conf. Ser 1257(2020).
[22] M. A. Sari, N. B. Wibowo, and D. Darmawan, "Pemetaan Percepatan Getaran Tanah Maksimum Dan Intensitas Gempabumi Di Kawasan Jalur Sesar Sungai Oyo Yogyakarta," J. Fis. 6(2) (2006) 101-107. 